\title{
Mapeamento geomorfológico para a bacia do Alto Curso do Rio Paraíba de acordo com as normas do Manual Geomorfológico do IBGE
}

\author{
Geomorphological mapping to the basin of the Upper Course of the Paraíba River de \\ according with the Geomorphological Manual of IBGE
}

FURTADO, A. V. B. D; SOUZA, de P. O. J

andrevictor_barcia@hotmail.com

\begin{abstract}
Resumo
Esse artigo tem o principal objetivo de abordar sobre a classificação dos diversos modelados encontrados no Alto curso do Rio Paraíba, a partir de uma análise da área de acordo com o Manual Geomorfológico do IBGE, 2009. A área em questão foi analisada a partir de uma escala de 1:100.000, compreendendo os táxons 2 e 3, representando respectivamente, parte do Planalto da Borborema e como expressado por CORREAA et al, 2010 as Unidades Geomorfológicas compreendidas como "Depressão Interplanáltica Paraibana" e "Maciços Remobilizados do Domínio da Zona Transversal". O mapeamento identificou 8 tipos de modelados, tendo como predominância as áreas de Pedimento, além da presença de topos dissecados ao sul e oeste e topos planos ao sul..
\end{abstract}

Palavras-chave: mapeamento, geomorfologia, Rio Paraíba.

\begin{abstract}
This article has the main purpose to address on the classification of the different modeled found in Upper course of the River Paraiba, from an examination of the area according to the IBGE Geomorphological Manual, 2009. The area in question was analyzed from a scale of 1: 100,000, comprising taxa 2:03, representing respectively, part of the Borborema Plateau and as expressed by Correa et al, 2010, geomorphologic units understood as "Inter plateau Depression Paraibana" and "Massive remobilized Domain of Cross Zone" . The result of this mapping may observed in Figure 03. The mapping identified eight types of patterned, with the predominant areas of pediment, and the presence of dissected tops to the south and west and flat tops to the south.
\end{abstract}

Keywords: mapping, geomorphology, Paraíba River.

\section{INTRODUÇÃO}

O principal objetivo desse artigo é discutir sobre o mapeamento geomorfológico no semiárido brasileiro, com o intuito de se realizar um mapa que aborde os processos que acarretaram nas formas de relevo encontradas na atualidade, seguindo os pressupostos do IBGE (2009) e buscando o uma forma de mapeamento regional. O mapeamento regional é de grande importância para o planejamento ambiental/territorial de uma área ocupada ou a ser ocupada, auxiliando também a análise de como como a paisagem irá se modificar, a partir da interação com as outras variáveis ambientais (LIMA 2014).

No Brasil houve uma demanda de mapeamento geomorfológico, fazendo-se o uso de somente imagens aéreas, pelas universidades, como discute o IBGE (2009). O projeto RADAMBRASIL foi responsável por padronizar os estudos sobre cartografia geomorfologia em território nacional, a partir do ano de 1971, anterior ao projeto RADAMBRASIL, os primeiros 
passos responsáveis pelos conhecimentos geomorfológicos brasileiros foram realizados com a vinda de professores estrangeiros ao Brasil com a vinda de estrangeiros, no período do governo de Getúlio Vargas. Um dos exemplos de responsáveis pelos estudos sobre os fenômenos geomorfológicos brasileiros está em Ab'Saber, responsável por caracterizar grandes áreas. O IBGE organiza os "cortes cartográficos", havendo, sendo padronizado de acordo com a Carta Internacional ao Milionésimo, sendo essas cartas subdivididas em outras cartas de 1:500.000, 1:250.000, 1:100.000, 1:50.000 e 1:25.000.

Foi escolhido o semiárido brasileiro para a realização desse estudo devido a uma necessidade de discursão e compreensão sobre tal região, tentando gerar uma contribuição para um melhor entendimento da paisagem semiárida a partir do mapeamento geomorfológico. Esse trabalho tem o dever de contribuir com os conhecimentos gerados sobre o semiárido brasileiro, podendo ser utilizado na realização de outros estudos e modelos.

A Bacia do Alto Paraíba foi selecionada, devido a sua localização no Cariri paraibano, sendo essa uma rede hidrográfica intermitente apresentando fluxo durante o período chuvoso. A compreensão geomorfológica sobre a bacia do Alto Paraíba poderá auxiliar o planejamento dos diversos recursos a serem encontrados naquela área. A escolha por trabalhar a partir de uma bacia hidrográfica dá-se por ela ser conceituadas como sistemas abertos, devido a uma grande diversidade de variáveis contidas, que podem atuar nessa localidade.

O IBGE (2009) define que para um mapeamento geomorfológico ideal, deve-se seguir determinados procedimentos, primeiramente, a acumulação de uma bibliografia sobre a área a ser estudada, envolvendo a mesma com os documentos cartográficos e imagens do local, interpretação temática, envolvendo a análise da drenagem do local, usando-se de uma escala que possa representar o local estudado, tais conhecimentos sobre o podem ser compreendidos como o "modelado".

Ao mesmo tempo, tem-se a preocupação na compreensão da escala, sendo essa variável de acordo com tamanho da área a ser estudada, sendo assim, isso irá impactar diretamente também na compreensão do tempo que tal fenômeno ocorrerá, na escala cartográfica e geográfica também segue a um "raciocínio" semelhante, como definido por MARQUES E GALO, 2014. Sendo a quantidade de detalhamento e tamanho da escala algo inversamente proporcional as escalas de tempo.

Os compartimentos geomorfológicos também podem ser entendidos como Unidades de Paisagem. Sendo a paisagem geográfica é um produto oriundo de como as interações antrópicas tendem a modificar a determinada porção do espaço, sempre de acordo com seu período temporal, refletindo assim, as disposições tecnologias atuantes. A formação do Espaço Geográfico se deve 
também entre a relação entre fenômenos climáticos e geológicos, que irão originar o relevo (VITTE, 2007).

É de importância que o profissional responsável pela elaboração de tal mapeamento tenha conhecimentos sobre os fenômenos a serem observados, como variações na vegetação, nas imagens de satélite, devido a vegetação presente no semiárido brasileiro ter variações intensas, em períodos chuvosos (presença de folhas) e nos períodos secos (ausência de folhas).

Tem-se o intuito, a partir desse mapeamento, de se obter os diversos modelados que podem ser encontrados na bacia do Alto Rio Paraíba, seguindo os regulamentos propostos pelo IBGE, 2009. Assim, foi realizado o mapeamento geomorfológico da bacia hidrográfica do Alto Rio Paraíba, na escala de 1:100.000.

\section{METODOLOGIA}

A área a ser escolhida a bacia hidrográfica do alto paraíba representando uma média de 400mm de chuva anuais, estando a sotavento do Planalto da Borborema, definido por PARAÍBA, 1985 como sendo um complexo gnáissico-migmatítico-granodiorítico caracterizada por conter áreas com as menores taxas de umidade do Brasil, como por exemplo, na cidade de Cabaceiras - PB. A vegetação encontrada na localidade se inclui no bioma da caatinga e solos da localidade compreendem-se por serem rasos com a rocha matriz exposta.

Fez-se o uso dos pressupostos metodológicos da abordagem sobre mapeamento geomorfológico do Instituto Brasileiro de Geografia e Estatística, o IBGE (2009) e a verificação a partir de imagens SRTM e cartas topográficas do Semiárido Nordestino, bem como a delimitação das principais bacias. Será realizada a elaboração do mapa na escala de 1:100.000, considerado assim um mapa geomorfológico de detalhamento, afim de ressaltar os principais processos e formas que ocorrem em tal espaço. O processamento de dados será realizado a partir do Arcgis 10.1, delimitando as principais áreas a serem estudadas e imagens aéreas do Cariri paraibano.

Escolheu-se trabalhar com imagens SRTM que tivessem uma resolução de 30 metros, devido ao seu detalhamento, precisão nas informações encontradas, quando comparado a outros tipos de imagem SRTM, com 90m, por exemplo (SOUZA E ALMEIDA, 2014).

O IBGE (2009) define que haja níveis que serão utilizados na classificação dos estudos ligados aos fenômenos geomorfológicos, sendo esses níveis taxonômicos variáveis de acordo com o tamanho da área de estudo. Sendo esses classificados com níveis de 01 a 06. ROSS aborda que tais níveis de classificação são fundamentais para se atribuir uma ordem que enfatize o tamanho da área. 
Os táxons escolhidos para serem utilizados neste trabalho, seguindo os regulamentos do IBGE, sendo esses responsáveis por atribuir "ordens de grandeza" aos elementos que serão verificados na paisagem geográfica serão o terceiro nível taxonômico, representando as unidades geomorfológicas, quarta ordem de grandeza, representando os modelados.

\section{RESULTADOS E DISCUSSÃO}

Durante a análise da Bacia do Alto Curso do Rio Paraíba (figura 01), os elementos principais que serviram para a realização da análise dos compartimentos geomorfológicos da área são a declividade e a altitude, sendo assim, a partir da visualização desses elementos, possibilitou que os compartimentos geomorfológicos identificados. A Figura 01 mostra os elementos da altitude e declividade, visto como um “MDE” (Modelo Digital de Elevação).

\section{MAPA DE LOCALIZAÇÃO BACIA HIDROGRÁFICA DO ALTO PARAÍBA}
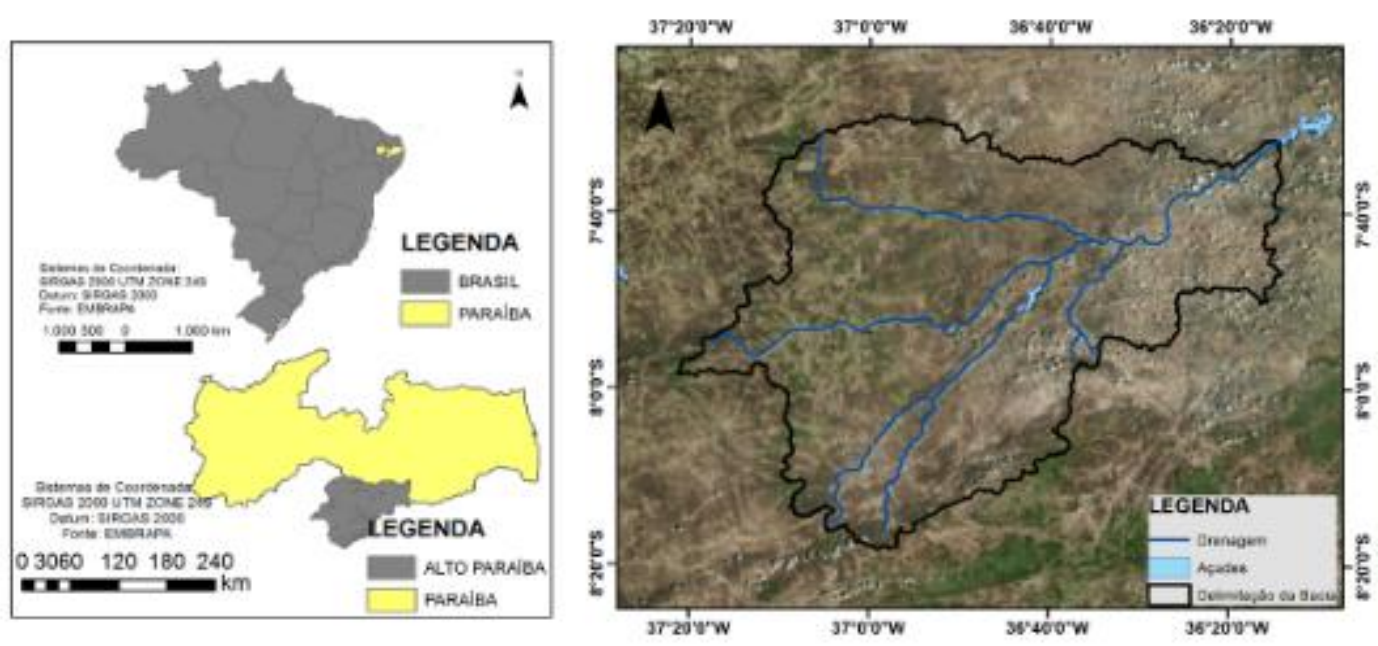

Figura 01. Mapa de Localização. Fonte: autor, 2016 


\section{MODELO DIGITAL DE ELEVAÇÃO E MAPA DE DECLIVIDADE}

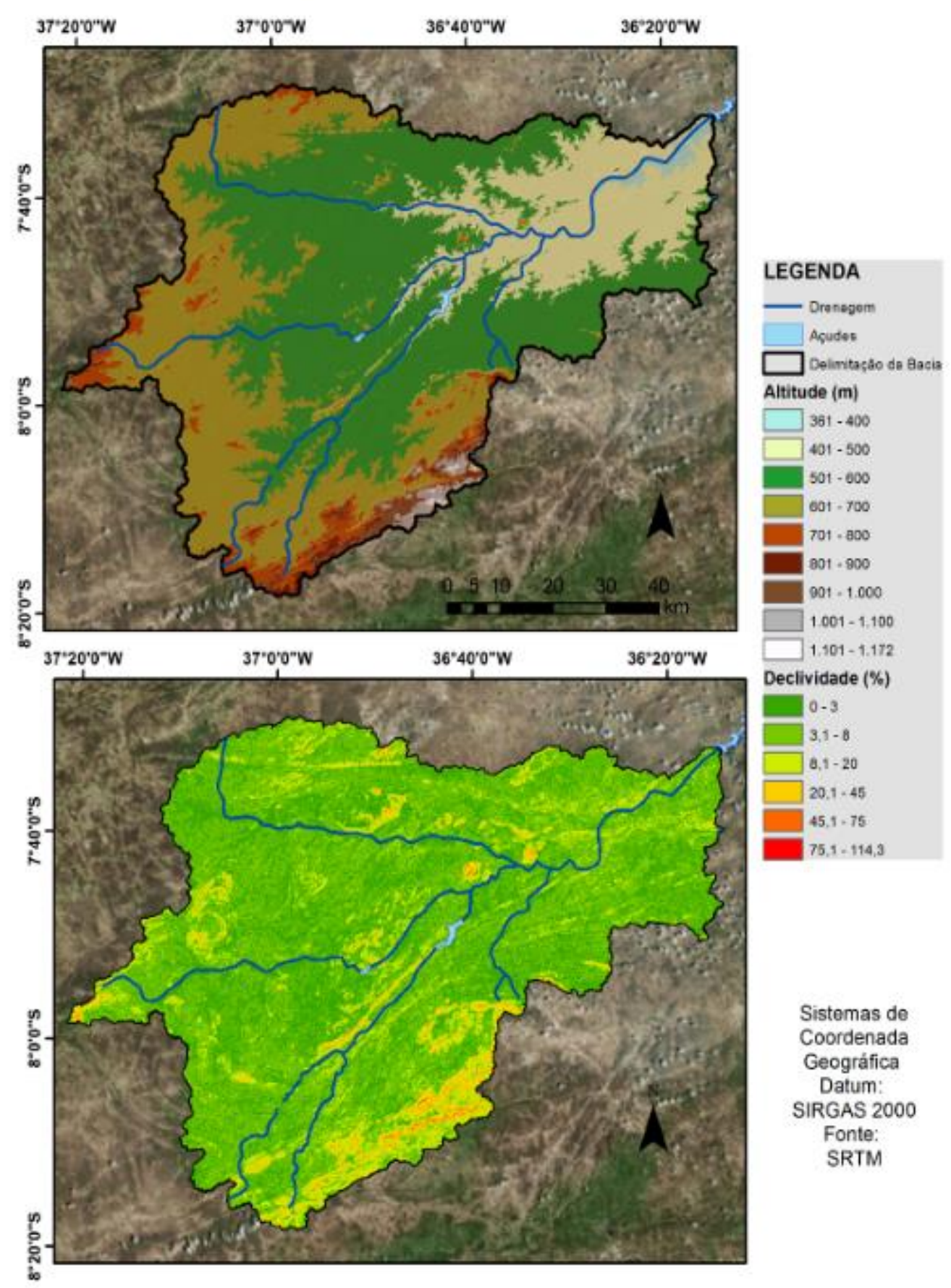

Figura 02. Mapa de Modelo Digital de Elevação e Declividade. Fonte: autor, 2016

Os táxons a serem analisados, de acordo com a Classificação do IBGE (2009), estão na ordem de relevância proposta, como sendo às Regiões Geomorfológicas, como sendo um resultante dos fatores geológicos de climáticos da área, sendo esse o segundo da ordem, sendo que a bacia se encontra em área de escudo cristalino, primeiro táxon, na unidade do Planalto da Borborema, 
segundo táxon. Unidades Geomorfológicas, inclusas no terceiro táxon, compreendidas como tendo formas e altimetria semelhante, sendo esses a Depressão Interplanáltica Paraibana e Maciços Remobilizados do Domínio da Zona Transversal.

Melo, 1956 (apud, CORRÊA et al, 2010) aborda que o Planalto da Borborema tem como principais características um antigo planalto, com uma parte rebaixada que apresenta resquícios do antigo relevo sedimentar e em sua outra parte altitudes que vão até 1000 metros. CORRÊA et al, 2010 discute também sobre os vários compartimentos que são encontrados, se destacam apenas dois, que definem o Alto Curso do Rio Paraíba, sendo esses Depressão Interplanáltica Paraibana e Maciços Remobilizados do Domínio da Zona Transversal, sendo compreendidos respectivamente como uma área que está delimitada de leste a oeste por encostas, por não apresentar perturbações tectônicas, contém feições aplainadas apresentam limites ao sul pelos Maciços Remobilizados do Domínio da Zona Transversal. A semiaridez favorece a não formação de regolitos, expondo as rochas a superfície e a área que mais recebeu interferência dos arqueamentos que incidem no planalto, com relevos mais íngremes, apresentando uma grande quantidade de maciços isolados, cristas e depressões Interplanálticas estreitas,

Durante a classificação das formas encontradas na área do Alto Curso do Rio Paraíba, podese perceber (figura 03) a presença de algumas formações como cristas simétricas, num total de quatro unidades geomorfológicas, encontrou-se uma totalidade de 8 inselbergues $\left(38 \mathrm{~km}^{2}\right), 1$ crista assimétrica $\left(31 \mathrm{~km}^{2}\right), 4$ cristas simétricas $\left(80 \mathrm{~km}^{2}\right), 1$ pontão $\left(25 \mathrm{~km}^{2}\right), 11$ topos dissecados $\left(348 \mathrm{~km}^{2}\right)$ e 1 topo plano $\left(100 \mathrm{~km}^{2}\right)$, sendo a maior parte da área compreendida como um pedimento $\left(5520 \mathrm{~km}^{2}\right)$.

A definição do IBGE, 2009 define cada o significado para cada compartimento geomorfológico, em seu manual. A Crista Assimétrica é abordada como também significando um tipo de Hogback, tendo suas encostas uma angulação superior a $30^{\circ}$ e tendo a maioria desses tipos de formação compostas por rochas metamórficas, Crista Simétrica é definida como possuindo um formato de linhas contínuas, estando isolada e marcada por declividades acentuadas, os Inselbergues são caracterizados por serem maciços residuais com uma angulação de aproximadamente $50^{\circ}$, coincidindo em áreas de depressão periférica e apresentando rochas metamórficas, o Pontão apresenta variadas características, como encostas íngremes, convexas e desgastadas por esfoliação, conhecidas também como formas residuais de batólitos. 


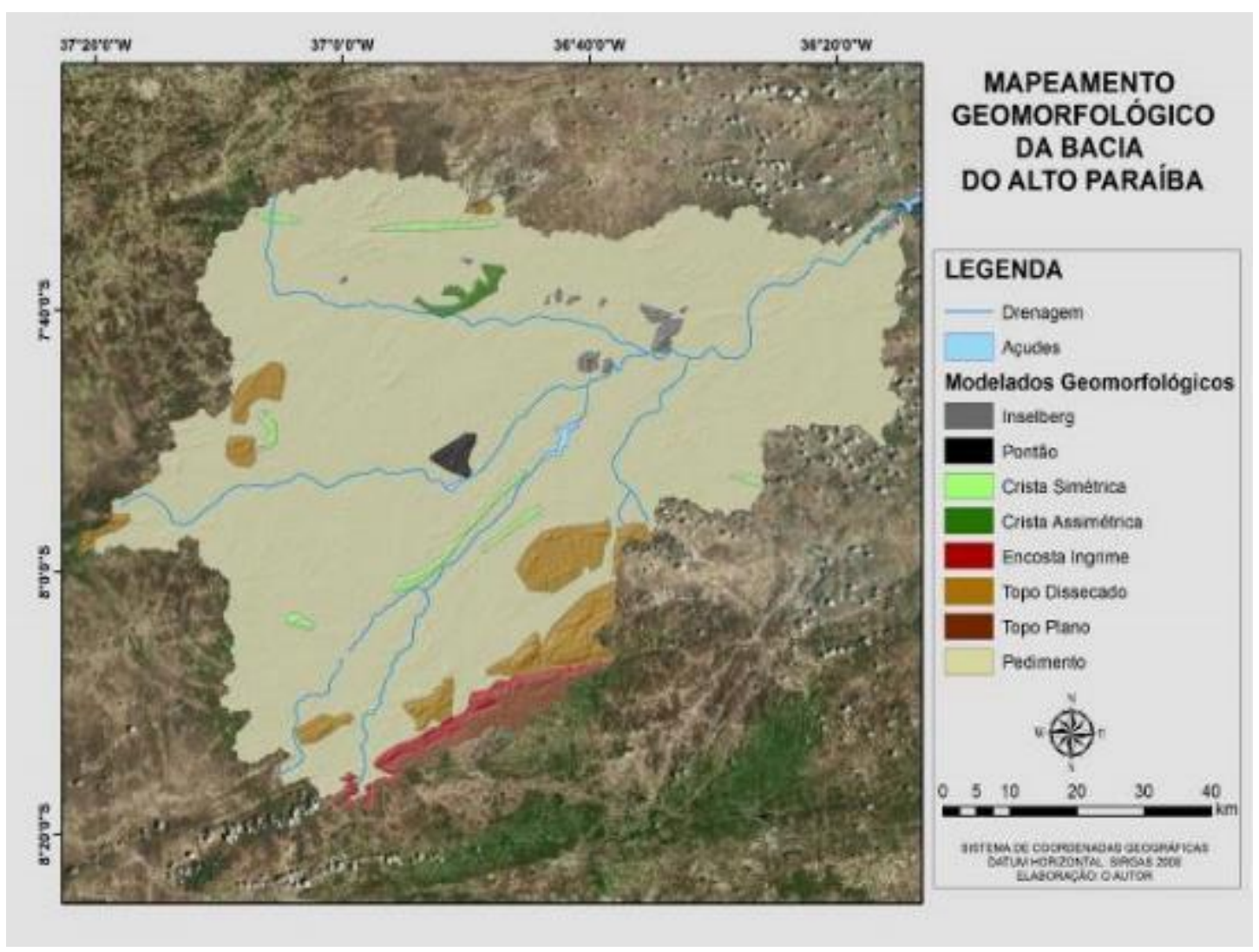

Figura 03. Mapa Geomorfológico da bacia do Alto Paraíba Fonte: autor, 2016

O Topo Plano está em uma área pertencente ao Planalto da Borborema. Os Topos Dissecados encontrados são característicos por serem caracterizados como homogêneos, sendo esses definidos como áreas que não apresentam controles estruturais marcantes, tendo morros e colinas predominantes. O Pediplano, compreendido como a maior área encontrada, é definido como uma superfície aplainada, suavizada, contendo material detrítico descontínuo sobre a rocha, não havendo deposição excessiva nem dissecação marcada, apresentando uma forte angulação em seus quando há contato com a vertente montanhosa. Na bacia do Alto Paraíba, isso pode ser encontrada na divisa da superfície pediplanada com o início do Planalto da Borborema, sendo essa na zona em sotavento. As figuras 02 e 03 abordam, respectivamente, a localização e os resultados gerais de todo o mapeamento, seguindo as diretrizes do manual do IBGE.

\section{CONSIDERAÇÕES FINAIS}

A partir do mapeamento geomorfológico feito realizado com as mais novas diretrizes do IBGE, Instituto Brasileiro de Geografia e Estatística, sendo possível se caracterizar as unidades geomorfológicas presentes na Bacia do Alto Paraíba, podendo-se chegar a uma conclusão de que a área estudada, estando inclusa em uma área que possuí pouca capacidade de absorção de água, 
devido a apresentar solos litóticos e vertissolos (LUCENA e PACHECO, 2016). Tais conhecimentos podem ser utilizados na gestão de recursos hídricos dessa localidade. As unidades morfoestruturais encontradas, definidas por CORRÊA et al, 2010, Depressão Interplanáltica Paraibana e Maciços Remobilizados do Domínio da Zona Transversal.

\section{REFERÊNCIAS}

CORRÊA et al. Megageomorfologia e morfoestrutura do Planalto da Borborema. Revista do Instituto Geológico, Ano 31 (1/2), 35-52. São Paulo: 2010.

IBGE, Instituto Brasileiro de Geografia e Estatística; Manual Técnico de Geomorfologia. $2^{\mathrm{a}}$ ed Rio de Janeiro: Gerência de Biblioteca e Acervos Especiais, 2009.

LIMA, G de. G. Análise comparativa de metodologias de mapeamento geomorfológico na Bacia do Rio Salamanca, Cariri Cearense. Dissertação de mestrado apresentado ao programa de pós-graduação em Geografia da Universidade Federal de Pernambuco, 2014.

LUNA et al. O Cariri paraibano: aspectos geomorfológicos, climáticos e vegetação. Disponível em: http://observatoriogeograficoamericalatina.org.mx/egal12/Procesosambientales/Climatologia/25.pdf . Acesso em: 15/08/2016

MARQUES, J. A.; GALO, T. B. L. A. Escala geográfica e escala cartográfica: distinção necessária. Bol. geogr., Maringá, v. 26/27, n. 1, p. 47-55. Maringá: 2008.

PARAÍBA, GOVERNO DO ESTADO. Secretaria de Educação. Universidade Federal da Paraíba. Atlas Geográfico da Paraíba. João Pessoa: Grafset, 1985.

ROSS, S. L. J. Suporte da geomorfologia aplicada: os táxons e a cartografia do relevo. Deopto De Geografia/USP. São Paulo.

SOUZA et al. Desertificação e seus efeitos na vegetação paraibana. Disponível em: http://www.mercator.ufc.br/index.php/mercator/article/viewFile/250/231. Acesso em: 15/08/2016 SOUZA, de P. O. J. Análise da precisão altimétrica dos modelos digitais de elevação para a área semiárida do Nordeste brasileiro. Revista do Departamento de Geografia - USP, Volume 30 (2015), p. 56 a 64. 62: São Paulo: 2010.

SOUZA, de P. O. J.; ALMEIDA, de M. D. J. Modelo digital de elevação e extração automática de drenagem: dados, métodos e precisão para estudos hidrológicos e geológicos. Bol. Geogr., v. 32, n. 2, p. 134-149, mai.-ago. Maringá: 2014.

VITTE, C. A. Desenvolvimento do conceito de paisagem e a sua inserção na geografia física. Mercator - Revista de Geografia da UFC, ano 06, número 11. Fortaleza: 2007 
Recebido em: 14/08/2016

Aceito para publicação em: 01/10/2016 